Revista de la red interuniversitaria de estudios sobre las literaturas rioplatenses contemporáneas en Francia

$13 \mid 2015$

Nuevas experiencias editoriales y literaturas

contemporáneas

\title{
Nuevas estrategias para la convivencia
}

\section{María Eugenia Romero}

\section{OpenEdition}

\section{Journals}

\section{Edición electrónica}

URL: http://journals.openedition.org/lirico/2049

DOI: $10.4000 /$ lirico.2049

ISSN: 2262-8339

\section{Editor}

Réseau interuniversitaire d'étude des littératures contemporaines du Río de la Plata

Referencia electrónica

María Eugenia Romero, « Nuevas estrategias para la convivencia », Cuadernos LIRICO [En línea], 13 | 2015, Puesto en línea el 15 diciembre 2015, consultado el 21 abril 2019. URL : http:// journals.openedition.org/lirico/2049; DOI : 10.4000/lirico.2049

Este documento fue generado automáticamente el 21 abril 2019.

\section{(c) $($ i) $(9)$}

Cuadernos LIRICO está distribuido bajo una Licencia Creative Commons Atribución-NoComercialSinDerivar 4.0 Internacional. 


\title{
Nuevas estrategias para la convivencia
}

\author{
María Eugenia Romero
}

Si las nuevas experiencias editoriales han contribuido a resguardar una cierta mirada sobre el libro y han asumido nuevas formas de acción es porque evidencian una reacción a lo que se fue dando en el campo editorial que, en los últimos tiempos, concentró la mayor porción de la actividad en unas pocas, poderosas y trasnacionales manos: las grandes casas de edición. Mientras que las primeras piensan al libro en diálogo con otros actores, estas lo conciben como mera mercancía y su accionar consiste en publicar en serie. Frente a este fenómeno que, por otra parte, no es solo propio de este campo sino un signo de los tiempos, hay un trabajo, muchas veces silencioso, de ciertos editores que no claudican y emprenden su tarea como un arte. Ellos han decidido dejar su impronta en el corpus de lo que publican y en la manera en que lo difunden, siendo conscientes, a la vez, de que su principal fortaleza es la obra, el texto que ponen a rodar. Dan continuidad de este modo a la esencia con la que empezó la historia misma de la edición desde los tiempos de Aldo Manunzio. En este sentido, no creo que haya una ruptura con lo que se entiende por edición, y por eso estas experiencias no me parecen "novedosas" sino simplemente muestran un reacomodamiento ante lo que generó la incorporación de ese nuevo y poderosísimo actor que marca tendencia, impone gustos, estilos, autores, domina el campo de la traducción y frente al cual es difícil competir. Entonces, lo que surgieron fueron, sí, nuevas estrategias para poder convivir y desmarcarse de esos modos salvajes y anónimos, y así poder subsistir sin perder lo más genuino de sí. Porque existe -y existió siempre- otro tipo de editor y la proliferación de estas llamadas "nuevas experiencias editoriales" es nada más que el testimonio de que la vieja manera de concebir al libro y la edición sigue viva, y lo nuevo consiste en procurarse un espacio de visibilidad. Y así, emulando a aquellos míticos editores de no hace tanto tiempo, como por ejemplo Sylvia Beach y su Shakespeare \& Co. en relación con la obra de James Joyce, o Ferlinghetti y la legendaria City Lights de San Francisco en relación a la de la Beat Generation, sólo para mencionar algunos, estos nuevos editores tratan también de encontrar su propio campo de acción. Para ello, las pequeñas editoriales, se caracterizan ante todo en hacer que se pueda leer una forma de concebir la escritura y la lectura a partir de sus catálogos. Sin embargo, postular una estética literaria ligada a las nuevas formas de editar libros, que 
como vimos no son tan "nuevas", me parece una hipótesis excesiva. El mismo concepto de "estética literaria" tiene para mi ecos rimbombantes y mucho de sonsonete. Por otra parte, decir que postulan una "estética literaria" sería a la vez constreñirlos, catalogarlos $y$, en fin, terminar empobreciendo algo que encuentra su riqueza justamente en su creatividad para traspasar límites. Como editora, hablar de "estética literaria" me resulta pretencioso : dejo esta cuestión a los críticos y a los profesores universitarios.

2 Muchas experiencias recientes son, por cierto, legibles en el nivel de la escritura. Esto me parece mucho más tangible y menos ambicioso que creer que creamos toda una "estética". En el caso que me atañe, el de Editorial Letranómada, es lo que se intenta evidenciar desde su pequeño catálogo, tal como hacen también otras editoriales argentinas como Fiordo, Viento de Fondo, Mardulce, Gog \& Magog y muchas otras. Hay en ellas un trabajo de construcción de catálogo que habla de un cierto modo de abordar y concebir la escritura y la lectura. En el armado de ese catálogo juega mucho la noción que el editor tiene de sí mismo como canal entre un autor y su obra y los modos de difusión para que esta encuentre el camino hacia su lector. El editor trata de ofrecer no ya un acopio sin sentido de títulos y libros sino un catálogo cuidado donde se exhibe una coherencia o se infiere una clave que permite al lector aventurarse también allí por donde el editor ha intentado hilvanar nexos o discontinuidades. Aportar el hilo que ponga a dialogar títulos y autores, generar curiosidad, esa es para mí la tarea primordial.

3 La punta de este hilo, en mi caso, me fue arrojada desde Portugal, país que visité en el 2007, para que pudiera enhebrarlo en el ojo de la aguja y así empezar a coser. Fue allí donde conocí a Gonçalo Tavares, quien generosamente me regaló varios de sus libros. Ya de regreso en la Argentina y apenas los hube leído, me di cuenta de que estaba ante un autor fascinante y ante una escritura potente que todavía era desconocida en mi país. Había encontrado el escritor con quien comenzar el proyecto que rondaba por mi cabeza desde hacía tiempo. Así, surgió en el 2008 la editorial Letranómada, con esa intención de acercar al público argentino traducciones de escritores contemporáneos en lenguas extranjeras, aún no conocidos en la Argentina, atentamente realizada por traductores y estudiosos, algunos de ellos también críticos o escritores.

4 No me conformaba la idea de leer traducciones que llegaban de afuera. Porque no es lo mismo leer traducciones españolas o mejicanas. Aunque muchas de ellas sean muy buenas hay cosas que disuenan. Esto es un reto, porque encarar traducciones aquí incrementa los costos pero creo que es fundamental a la hora de encarar seriamente estos proyectos. Por otro lado estoy en contra de la traducción en una lengua neutra, lavada, en un español "global" que atenúe las diferencias para poder ser vendida a todos los países. Me interesa la traducción como escritura. Soy consciente, además, de que al elegir qué traducir o qué desechar estoy intentando armar un mapa de lo que pienso que vale la pena poner a disposición del lector. Más allá del límite económico que me impide publicar todo lo que quisiera, trato de elegir autores cuya obra tenga una sutileza distinta de la que hallaría en un autor argentino, pero siempre teniendo en mente a los lectores argentinos, mis cómplices o detractores. Muchas de las nuevas editoriales comparten esta actitud con respecto a la traducción interviniendo así en este campo, lo que ayuda a las editoriales a personalizarse. En el caso de Letranómada, la traducción literaria es un objetivo que perseguimos como política editorial.

5 Editamos sobre todo narrativa y algo de poesía y ensayo. Pensamos, sin embargo, que todo encasillamiento genérico empobrece cualquier abordaje de la literatura. Por eso nuestras obras suelen desbordar estos estrechos límites. Nos esforzamos también por 
poner especial cuidado en el diseño y el aspecto material del libro, como forma especial de respetarlo y amarlo.

6 Con respecto a la colección argentina, que vino poco después, la costura que se deja entrever es cierta línea de autores que muestra al mismo tiempo un inquietante grado de marginalidad, pero que además están dentro del canon de un modo u otro. Creo que sus títulos comparten también una cierta hibridez como el caso de las obras de Héctor Libertella, Néstor Sánchez, Andrés Allegroni, Hugo Savino, Remo Bianchedi y Laura Estrin.

7 Algo digno de mencionar es el modo de relacionarse que tienen estas editoriales con sus autores, las obras y con los otros actores del mercado como libreros, distribuidores, factores importante a la hora de trabajar los catálogos. Los nuevos editores suelen construir un sistema literario "íntimo", donde los actores mantienen estrechas relaciones entre sí, en virtud de una "complicidad" que consiste en compartir ciertos trechos o momentos en la hoja de ruta. Hay mucha más proximidad, no solo a nivel de lo que a veces puede ser la identificación de la casa editora con la obra de un determinado autor, como en mi caso con la obra de Tavares, sino también en el hecho de tener un trato más personal y cercanía tanto estética como humana. A nosotros nos complace editar la mayor cantidad de obras de un autor para poder mostrar un derrotero, con sus momentos de aciertos, de dudas, de repliegues, de cambios. Tavares, por ejemplo, tiene novelas más "tradicionales" y también obras de géneros híbridos en donde experimenta con distintos materiales que difícilmente encontrarían una vía en editoriales grandes que, con sus prejuicios, las considerarían no comerciales o menores. Para nosotros no existe ese tipo de diferencias.

8 Por otro lado, la manera de difundir es más directa, hay más diálogo con los libreros porque se busca el lugar que pueda efectivamente vender ese material, que pueda ser una boca hacia otra boca. Otro ojo. Nos preocupamos minuciosamente de trabajar cada libro, por ejemplo, a través de charlas y talleres gratuitos y libres. Creo que esta relación de intimidad entre los distintos actores que intervienen intenta definir qué clase de "complicidad" se comparte. Los libros del catálogo dan las pistas. El lector terminará el recorrido.

Con esto en mente el editor baja al mercado y deja su material en los anaqueles. Pienso que ser legible a nivel de la escritura no significa necesariamente crear valor literario. Algunos editores lo podrán lograr, pero creo que para no encandilarnos hay que tener presente que el concepto de "valor literario" es un concepto autoritario y presuntuoso, y que como tantas listas o cánones, es movible, arbitrario y depende de quien lo arma, o dentro de qué contexto se decrete o a qué tribu ese valor responde. No es lo mismo el valor literario en ciertos círculos de Buenos Aires que en Mendoza o en Córdoba o que en un pueblito de Formosa. No sé si la función de un editor sea la de crear valor sino básicamente la de ser honesto. Muchas veces se crean modas que pasan como valor... aunque pronto quedarán desmentidas. Hay que tener mucho cuidado.

Creo que lo que sí puede hacer un editor es volver visibles otras posibilidades. Hacer de la escritura y la lectura un pleno de direcciones y caminos potenciales. Pero eso se vuelve evidente recién con el tiempo. Entonces, la hipótesis que se podría formular a partir del análisis de un catálogo es simplemente la de encontrar cuál es el hilo que hilvana la complicidad entre autor, obra y lector : aventurar el nexo que se está tratando de tramar. El editor busca cómplices, compañeros de ruta y también detractores. 
11 Si muchos lograran desanudar por completo este meollo, entonces el próximo paso del editor será indefectiblemente defraudarlos. Nunca ser obvio o editar lo "esperable" porque ahí se cae en la fosilización. Se pierde vigor. El pequeño editor sabe también cuándo ser ubicuo. Siguiendo al editor italiano Roberto Calasso, la edición como arte consiste en un dar forma y su esencia es la de intentar hacer cosas que en principio no parecen factibles.

12 Por eso y con respecto al otro actor importante que se ha incorporado al mundo de la edición en los últimos tiempos, las nuevas tecnologías, muchos de estos nuevos editores las han incorporado transformándolas en genuinas experiencias literarias : basta visitar algunos blogs como el de Palabras Amarillas para corroborarlo.

13 Pero confieso que en mi caso esa incursión o esa discusión no me apasiona. A mí, particularmente, me interesan los libros pero más allá de lo que cada uno piense o haga, la historia seguirá su rumbo... Veo a las nuevas tecnologías simplemente como nuevas herramientas, no como un valor en sí. Su valor depende exclusivamente del que la persona le dé.

14 Se dice que las nuevas tecnologías permiten un mayor acceso a los textos. Ponen a disposición una cantidad de textos, debates, crean un mayor contacto con autores o entre los mismos lectores. Pero habría que considerar en definitiva qué surge de ese acceso supuestamente mayor. Y qué es lo que las nuevas tecnologías dejan afuera. Me pregunto: $i$ se lee o se escribe mejor por el solo hecho de tener acceso a una mayor cantidad de material y de una manera más rápida ? No lo sabemos todavía.

Dante necesitó a Virgilio... Teseo, a Ariadna... Creo que ningún texto solo, en el soporte que sea alcanza por sí mismo. La aventura de la escritura y la lectura es que necesitamos de otros. A lo largo de la historia hemos constatado la importancia de contar con guías, desde un profesor que nos dé una pauta a un amigo que nos recomienda un libro, o de una figura que admiramos y de la que sabemos que le gusta tal o cual autor, tal o cual texto. Por eso si las nuevas tecnologías dan acceso a más personas y ponen a disposición más material, eso en principio no es ni bueno ni malo, porque siempre va a depender del grado de intimidad o compromiso que tengamos con eso. De cómo nos dejemos introducir en un mundo en donde se necesita siempre dialogar, donde la persona deberá estar siempre presente.

16 Para mí las nuevas tecnologías no compiten necesariamente con el libro. Son un complemento o en última instancia, otra cosa. El problema que les encuentro es que un mar de títulos y opciones con su aparente magnetismo y facilidad muchas veces dispersa... Crea una aparente sensación de diálogo. Pero eso mismo también pasa con el soporte libro, como cuando uno entra a las grandes cadenas y se pierde entre millones de títulos, pilas de best sellers y novedades, numerosos carteles, ruidos. A mí, sinceramente, me dan ganas de huir. Por suerte vivo apartada en la sierra y cuando voy a la ciudad, nada como el entusiasmo y la pasión que despierta el recorrer las pequeñas librerías especializadas donde uno puede pasar mucho tiempo mirando, eligiendo y charlando con sus libreros.

17 Las nuevas tecnologías pueden encandilar pero también ser volátiles y de éxito inmediato generando un interés efímero. Y en nuestra profesión lo que más cuesta es mantenerse en el tiempo. Eso es un mejor parámetro para mí que la cuestión del soporte. A mí, como dije, me interesa el objeto libro, las hojas ajadas, los subrayados (que solo en un libro pueden ser verdaderamente "míos"), el olor, el lugar en el que lo pongo en la biblioteca, los libros 
que elijo para llevar a la mesita de luz. Pero ante todo el libro tiene un encanto del que las nuevas tecnologías carecen. Puede ser prestado, regalado, heredado. $Y$ esto quiere decir que hay que involucrarse : la acción de pensar qué, por qué y a quién legar un libro permanece viva en la mano que se extiende hacia otra mano. Allí veo una conexión profunda que me parece falta en las nuevas tecnologías.

La experiencia de las nuevas editoriales se basa en ese vínculo. Un nexo de complicidad, humano e íntimo que ellas crean entre autor, editor, lector y libro y que se hacen visible a partir de un catálogo. Ese es el pequeño secreto.

\section{AUTOR}

MARÍA EUGENIA ROMERO

Editora de Letranómada 